\title{
Attrition Rate and Reasons for Attrition in Medicals Schools Worldwide- an Analysis
}

\author{
Article by Arulsamy Anand \\ Vice Chancellor, Texila American University, East Bank Demerara, Guyana \\ Email:vc@tau.edu.gy
}

\begin{abstract}
Background: Students attrition in Medical schools is a major concern, attrition rates are one of the important indicators being used by the accrediting bodies to measure the medical schools' performance. Having understood the gravity of this issue, medical schools are paying great attention to curb the attrition rate. This review aims to understand the various reasons identified by worldwide medical schools for the attrition of students. The reasons identified by different medical schools and the attrition rate, detailed in this study will be of great value to the medical school administrators to address the attrition in their respective medical schools.

Methods: Based on the determined eligibility criteria, six electronic databases were searched in the year 2018 for relevant articles. Nine relevant articles were chosen for the study, the articles where chosen based on the experience of different medical schools from different countries, which include the UK, Nigeria, Jeddah, Croatia, Pakistan, Ireland, Kingdom of Saudi Arabia, Israel and Malaysia. Articles that reported the attrition rate and the reasons were chosen. An analysis was done to understand the experience of the worldwide medical schools and the reason attributed to attrition.

Results: A careful analysis of nine articles reveals that the attrition rate varied from $3.8 \%$ in Saudi Arabia to 26\% in Croatia medical schools. UK medical school showed an attrition rate of 14\%, Ireland5.7\%, Nigeria- 7.8\%, Jeddah- 20.8\%, Croatia- 26\%, Pakistan-16\%, Kingdom of Saudi Arabia-3.8\%, Israel- $12.6 \%$ and Malaysia- $5.9 \%$. An average attrition rate of $12.5 \%$ was found in all schools from different countries.

The major reason for attrition is found to be academic difficulty followed by absenteeism, isolation, personal problems, psychological problem, and financial problems.

Conclusion: Investment into medical education is expensive compared to the other programs and dropping out from medical schools has multiple implications. The individual student has a major setback in life, the society loses the professional manpower. The medical school loses its revenue and waste its professionals time. In most cases it is observed that students drop out because of academic difficulty hence, it is imperative that medical schools pay more attention to screening students academically and psychologically. It should also create strong students support system and academic mentoring to minimize dropouts.
\end{abstract}

Keywords: Attrition Rate, Reasons for attrition, Academic difficulty, Dropouts.

\section{Background}

Attrition in an academic institution is not something new, but attrition in a medical school needs to be dealt with appropriately. Enrolling into medical school represents the start of a demanding and stressful period for students. Despite a multitude of social, academic, and emotional stressors, most students successfully cope with a complex new life role and achieve academic success. Other students are less able to successfully manage this transition and, sooner or later, decide to withdraw themselves, or face dismissal by the medical school.

Attrition rates are one of the important indicators being used to measure university performance. In part, this reflects the fact that student attrition represents an inefficient use of resources. If students who leave the school before graduating cannot be used in the labor market whatever human capital they have gained during their courses [1].

For the medical profession, dropout results in a loss of useful contribution and impacts on medical workforce planning. A high attrition rate can affect the academic reputation of a medical school and 
staff morale and may have financial consequences with subsequent impact on research and teaching. Most important of all, however, is the effect of leaving medicine on the individual student - dropout has considerable financial, social and emotional consequences and can cause great distress, low morale, and poor self-esteem.

Addressing the attrition in medical school requires an understanding of the cause of attrition and the attrition rate. This article analyzes the reason for attrition in medical schools located in different countries

\section{Methods}

\section{Literature search}

As it is a literature review, ethical approval is not required for this project. Articles from the various digital database were sourced, 78 related articles were identified from ResearchGate, Pubmed, Biomed Central and Google scholar. Research Studies reported in languages other than English were omitted from this review. No date restrictions were used. This literature search was conducted and completed in early 2018. The references of the included articles were examined to identify additional relevant studies.

\section{Review procedure}

The initial search strategies yielded 78 original candidate articles, but after abstract review, 38 articles remained eligible for inclusion. Among the common reasons for article exclusion were the following: the articles did not report the attrition rate and did not state any reasons.

After reviewing full texts, an additional 19 studies were excluded for reasons including nonmedical student learners, insufficient characteristics of attrition, Non- English, not peer-reviewed or scholarly and Conference presentation (Figure 1). As a result, 19 articles were selected for inclusion in this review. 


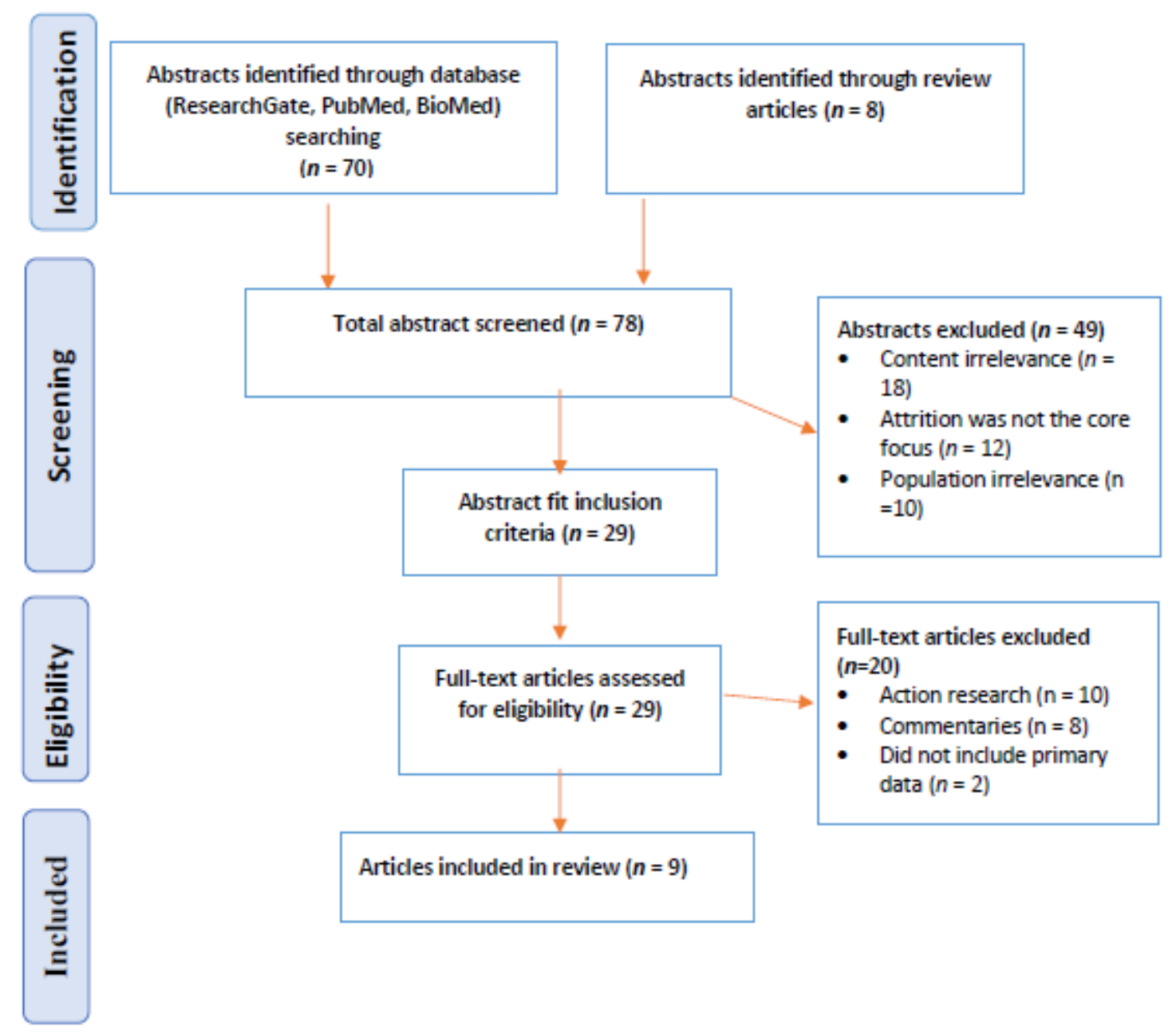

Figure 1. Search process by data source, stage, and yield

\section{Eligibility criteria}

To examine the reasons attributed by medical schools for attrition and the attrition rate detailed by them. The eligibility criteria are given as the inclusion and exclusion criteria in the below table.

Table 1. Inclusion and exclusion criteria

\begin{tabular}{|l|l|l|}
\hline Criterion & Inclusion & Exclusion \\
\hline Language & English & Non- English \\
\hline Type of Article & Peer-reviewed & $\begin{array}{l}\text { Non-peer reviewed or } \\
\text { scholarly, Conference } \\
\text { presentation }\end{array}$ \\
\hline Type of Studies & $\begin{array}{l}\text { Quantitative (e.g. controlled studies, before and after } \\
\text { studies, post-course studies, longitudinal studies); } \\
\text { Qualitative (e.g. action research, case studies); reviews (e.g. } \\
\text { meta-analyses, scoping reviews); }\end{array}$ & \\
\hline Study Focus & Attrition rate and the reasons for attrition & $\begin{array}{l}\text { Not medical education } \\
\text { related; other health } \\
\text { Sample } \\
\text { Sagessions (e.g. } \\
\text { pharmacy, nursing, } \\
\text { veterinary) }\end{array}$ \\
\hline
\end{tabular}




\section{Results}

The scope of published studies on attrition and reasons for attrition in medical schools. There have been numerous studies on attrition and the reasons for attrition, however, this study is unique mainly because it offers a combined view of all studies related to attrition.

\section{Countries of study}

The articles were chosen from studies conducted in different medical schools spread across the world. This includes UK $(n=1)$, Nigeria $(n=1)$, Jeddah $(n=1)$, Croatia $(n=1)$, Pakistan $(n=1)$, Ireland $(n=$ 1), Kingdom of Saudi Arabia $(n=1)$, Israel $(n=1)$, and Malaysia $(n=1)$.

\section{Level of medical education}

The review and searches included all 4 years of medical school (including preclinical and clerkship).

\section{Attrition rate and reasons for attrition in medicals schools worldwide}

\section{Studies conducted in the UK medical school}

This study retrospectively assessed the records of all students at Leeds School of Medicine who left the course prematurely between 1983 and 1992. The demographic data of the leavers were compared with those of all students entering the school during the 10 years studied. A-level examination choices and results of the leavers were compared with those of a control group of all students who entered the school in 1990.

Attrition Rate: The attrition rate over the 10 years was $14 \%$ (283 students), with more males than females leaving.

Reason for Attrition: Fifty-three percent of leavers were asked to withdraw from the course for academic reasons; the rest left voluntarily. Thirty percent had personal problems, $9 \%$ had a combination of academic and personal problems and $8 \%$ had health problems (psychological difficulties were the commonest). [10]

\section{Studies conducted in the irish medical school}

Attrition Rate: Overall attrition rate was 5.7\% (45/779) in 6 completed cohorts when students who transferred to other medical courses were excluded. Students from Kuwait and the United Arab Emirates had the highest dropout rate $(R R=5.70,95 \%$ Confidence Intervals 2.65 to $12.27 ; p<0.0001)$ compared to Irish and EU students combined. North American students had a higher dropout rate than Irish and EU students; RR $=2.68$ (1.09 to 6.58; $\mathrm{p}=0.027)$ but this was not significant when transfers were excluded $(\mathrm{RR}=1.32(0.38,4.62) ; \mathrm{p}=0.75)$. Male students were more likely to drop out than females (RR 1.70, .93 to 3.11) but this was not significant ( $\mathrm{p}=0.079$ ).

Reason for attrition: Absenteeism was documented in $30 \%$ of students, academic difficulty in $55.7 \%$, social isolation in $20 \%$, and psychological morbidity in $40 \%$ (higher than other studies). Qualitative analysis revealed recurrent themes of isolation, failure, and despair. [8].

\section{Studies conducted in the nigerian medical school}

Attrition Rate: A pilot analysis was undertaken using the records of students who failed at medical school as a result of the inability to pass the second MBBS examination at Ebonyi State University, Abakaliki, Nigeria, between 2002 and 2007. Some of these students were interviewed using a structured questionnaire.

Data analysis showed that $58(7.8 \%)$ of the students admitted into preclinical class withdrew from their study. Thirty-six $(62.1 \%)$ were males and the rest were females.

Reason for Attrition Thirteen of those withdrawn was interviewed, and 53.8\% of them believed they had poor academic ability, while $15.4 \%$ attributed their withdrawal to family pressure.[3]

\section{Studies conducted in the jeddah medical school}

Analysis of Attrition over a 7-Year Period at the Faculty of Medicine, King Abdulaziz University, Jeddah 
The purpose of this study is to determine the attrition rate at the Faculty of Medicine from 1996 to 2002. Review of all students' records (males and females) matriculated during the study period. Nongraduating students' records were further examined to differentiate academic from non-academic attrition and to determine the length of stay in the faculty, frequency of failing examinations and curriculum level at leaving the faculty.

Attrition Rate: out of 1,725 students admitted to the faculty, 359 left the faculty without graduation. This gives an attrition rate of $20.8 \%$.

Reason for Attrition: $10.9 \%$ for academic reasons. For the non-academic attrition, $81.3 \%$ of the students leave after one year, $28.7 \%$ of them without failing any examination. In the academic attrition group, $50.5 \%$ of the students are dismissed after 2 years and another $25.5 \%$ after 3 years. $73.4 \%$ of these students fail 4 times before being dismissed. $50.5 \%$ of the academic attrition is in the first year of the curriculum. [2].

\section{Studies conducted in croatia medical school}

To determine attrition and predictors of academic success among medical students at the University of Split, Croatia. The researchers analyzed academic records of 2054 students enrolled during the 19792008 period.

Attrition Rate: They found that 26\% (533/2054) of enrolled students did not graduate.

Reason for attrition: The most common reasons for attrition were 'personal' (36.4\%), transfer to another medical school (35.6\%), and dismissal due to unsatisfactory academic record (21.2\%).[9].

\section{Studies conducted in the pakistan medical school}

Attrition Rate: Study conducted during the six years between 1996 and 2001, the school enrolled 396 students out of which 64 students left which equals to $16 \%$.

Reason for Attrition: A total of 6 (17.1\%) female and 7 (24.1\%) male students voluntarily left the course, and $29(82.9 \%)$ female and $22(75.9 \%)$ male students withdrew from the course for academic reasons. Twenty-seven $(93.1 \%)$ female and $19(86.4 \%)$ male students were asked to withdraw due to poor academic performance. Five $(7.8 \%)$ students left medicine due to psychiatric or psychological problems. A similar number of students left after being admitted into some other institution. Four (6.3\%) students left medicine for financial reasons, and a similar number migrated overseas. [5].

\section{Studies conducted in the saudi arabian medical school:}

A cross-sectional study of all students admitted to the College of Medicine at KSU during 5 academic years (1994 to 1998) was conducted in 2004.

Attrition Rate: Overall, 28 students (3.8\%) dropped out,

Reason for Attrition: There was a significantly greater frequency of dropping out in the Low GPA group $(10 / 120 ; 8.3 \%)$ compared with the High GPA group $(18 / 619 ; 2.9 \%$ : OR 3.035 [95\% CI: 1.37, 6.75], $\mathrm{P}=0.01$ ) [1].

\section{Studies conducted in the israel medical school}

The study sought to identify variables from the demographic, socio-economic, academic and personal background of medical students in order to reveal possible predictors of drop-out from medical school. The research included 443 students who were admitted to Ben Gurion University (BGU) Medical School during its first 10 years, 1974-1983.

Attrition Rate: The study found out that $12.6 \%$ dropped out of BGU

Reason for Attrition: It was found that the permanent drop-out rate in BGU Medical School (12.6\%) is relatively high and mainly due to academic failures. Of all admitted students $11.3 \%$ do not graduate on time due to academic reasons. [7].

\section{Studies conducted in the malaysian medical school}

Attrition Rate: Among the 10 student cohorts between 2002 and 2007, a total of 112 out of 1,890 students withdrew from the medical program with more male than female students. The attrition rate among medical students in IMU between 2002 and 2007 was 5.9\%. 
ISSN: $2519-500 \mathrm{X}$

Reason for Attrition: Students with 'high' academic banding of entry qualifications and poor English qualification grades exhibited higher rates of attrition. [11]

\section{Discussion}

Studies predominantly attribute academic difficulty as the major cause of attrition. Studies have also shown that students enrolling with lower level GPA struggle in academics and are at risk of dropping out, the other attributes like absenteeism, isolation, and depression are added to the vows of poor academic performance.

Attrition can only be addressed when the issues related to academic performance and student satisfaction are addressed. Some of the measures are:

Entry requirement: Students has to be screened appropriate predictive screening test which will adequate assess students' suitability to the medical program.

Non-cognitive skills: students should be assessed on the non-cognitive skills particularly focusing on the coping skills and emotional quotients.

Students Support Service: Every student should be assigned to a student support service office, who will render all support to the students. He/She will shadow him/her throughout the program, particularly during the pre-clinical years.

Faculty Advisers: Every student should be assigned with a Faculty adviser, who will monitor the students closely and also be the first point of contact for any academic related concerns.

Academic Mentoring: This is the most important aspect of retention, which will guarantee almost $90 \%$ retention or more.

Feedback system: Regular feedback from the students is the most important activity to be encouraged in any medical school. Addressing the students concerns on the feedback will resolve many trivial concerns but keep the student satisfied.

Monitoring and Independence: Many teachers believe that students should fend for themselves and should have self-motivation to do a medical course, but this is not always true. Students need constant monitoring and guidance, at least during the pre-clinical years.

\section{Limitations of the study}

1. Focus on a few schools in a country: The data chosen for the study are only from a few schools in a country, hence it may not represent the countries national data.

2. Variation in duration: The study coverage period varied in each of these studies spanning from 5 years to 30 years.

3. Variation in the number of the students studied: As the study period varied the number of students studied also varied.

\section{Conclusion}

The medical profession is a taxing field. Many students who enter medical school often leave the course halfway upon realizing that they are not capable. Some are forced to leave, owing to financial or personal situations. Attrition is not uncommon in universities, but attrition rates are highest in medical schools. Medical students require a support system, which will help them deal with the stress that comes along with the course. When they are psychologically supported, their academic performance will also improve. While it is impossible to completely abolish attrition in medical schools, it is very conceivable to bring it down.

\section{Disclaimer}

This disclaimer informs readers that the views, thoughts, and opinions expressed in the text belong solely to the author, and not necessarily to the author's employer, organization, committee or other group or individual. 


\section{References}

[1]. Al-Mazrou AM. Does academic performance in the premedical year predict the performance of the medical student in subsequent years? J Family Community Med. 2008 May-Aug;15(2):85-9.

[2]. Bakhsh TM. Analysis of Attrition over a 7-Year Period at the Faculty of Medicine, King Abdulaziz University, Jeddah. Journal of King Abdulaziz University-Medical Sciences. 2008 Oct 1;15(4):49-57.

[3]. Dewji R, Gnanappiragasam D, Dewji A. Challenges of medical student underperformance. Med Education Online. 2014 Nov 24; 19:26041.

[4]. Egwu OA, Anyanwu GE. Five-year survey of medical student attrition in a medical school in Nigeria: a pilot study. Advances in medical education and practice. 2010; 1:53.

[5]. Huda n, agha s. Attrition in medical college: Experience at Ziauddin Medical University in Pakistan. Education for Health-abingdon-carfax publishing limited- 2004 Jul;17(2):232-5.

[6]. Johnes G, McNabb R. Never give up on the good times: student attrition in the UK. Oxford Bulletin of Economics and Statistics. 2004 Feb;66(1):23-47.

[7]. Lazin R, Neumann L. Student characteristics as predictors of drop-out from medical school: admissions to Beer-Sheva over a decade. Medical Education. 1991 Sep;25(5):396-404.

[8]. Maher BM, Hynes H, Sweeney C, Khashan AS, O'Rourke M, Doran K, Harris A, O'Flynn S. Medical school attrition-beyond the statistics a ten-year retrospective study. BMC medical education. 2013 Dec;13(1):13.

[9]. Maslov Kruzicevic S, Barisic KJ, Banozic A, Esteban CD, Sapunar D, Puljak L. Predictors of attrition and academic success of medical students: a 30-year retrospective study. PLoS One. 2012 June: e39144.

[10]. Simpson KH, Budd K. Medical student attrition: a 10-year survey in one medical school. Medical Education. 1996 May;30(3):172-8.

[11]. Yadav H, Yusoff N, Tan KL. Attrition of Medical Students in International Medical University-2002 to 2007. South East Asian Journal of Medical Education. 2012;6(1):43. 